\title{
Corrigendum: Touching! An Augmented Reality System for Unveiling Face Topography in Very Young Children
}

\author{
Michiko Miyazaki ${ }^{1,2 *}$, Tomohisa Asai ${ }^{3}$ and Ryoko Mugitani ${ }^{2,4}$ \\ ${ }^{1}$ Department of Social Information Studies, Otsuma Women's University, Tokyo, Japan, ${ }^{2}$ NTT Communication Science \\ Laboratories, Atsugi, Japan, ${ }^{3}$ Advanced Telecommunications Research Institute International (ATR), Kyoto, Japan, \\ ${ }^{4}$ The Faculty of Integrated Arts and Social Sciences, Japan Women's University, Kanagawa, Japan
}

Keywords: psychology, development, body image, augmented reality, face, body topography

\section{OPEN ACCESS}

Approved by:

Frontiers Editorial Office,

Frontiers Media SA, Switzerland

${ }^{*}$ Correspondence:

Michiko Miyazaki

myzk@otsuma.ac.jp

Received: 24 June 2019

Accepted: 25 June 2019

Published: 12 July 2019

Citation:

Miyazaki M, Asai T and Mugitani R (2019) Corrigendum: Touching! An

Augmented Reality System for Unveiling Face Topography in Very

Young Children.

Front. Hum. Neurosci. 13:236. doi: 10.3389/fnhum.2019.00236

\section{A Corrigendum on}

Touching! An Augmented Reality System for Unveiling Face Topography in Very Young Children

by Miyazaki, M., Asai, T., and Mugitani, R. (2019). Front. Hum. Neurosci. 13:189. doi: 10.3389/fnhum.2019.00189

In the Acknowledgments section of the original article, the names of two individuals were spelled incorrectly. The first error is Ayano Shiina; the correct spelling is Ayana Shiino. The second error is Koichi Matsuda; the correct spelling is Kouichi Matsuda.

The authors apologize for the oversight and confirm that this does not change the scientific conclusions of the article in any way. The original article has been updated.

Copyright (c) 2019 Miyazaki, Asai and Mugitani. This is an open-access article distributed under the terms of the Creative Commons Attribution License (CC BY). The use, distribution or reproduction in other forums is permitted, provided the original author(s) and the copyright owner(s) are credited and that the original publication in this journal is cited, in accordance with accepted academic practice. No use, distribution or reproduction is permitted which does not comply with these terms. 